\title{
Reflexividade ética na carreira, valores de experimentação e curiosidade em estudantes universitários
}

\section{Ethical reflexivity in career, values of experimentation and curiosity in university students}

\author{
Ana Catarina Costa, Ana Daniela Silva, Cátia Marques \\ Universidade do Minho
}

\begin{abstract}
Resumo
O presente artigo explora se os níveis de reflexividade ética podem explicar a existência de valores de experimentação ou de respostas adaptativas de curiosidade. Participaram no estudo 488 universitários de ambos os sexos (73.1\% raparigas), com idades compreendidas entre os 18 e os 53 anos $(\mathrm{M}=21.9, \mathrm{DP}=$ 4.1), a frequentar diferentes anos e cursos universitários. Os resultados de análises de regressão linear hierárquica indicam que existem associações significativas entre os níveis de reflexividade ética na carreira e a curiosidade e que não existe relação entre os níveis de reflexividade ética na carreira e a subfunção experimentação.

Palavras-chave: Reflexividade ética; curiosidade; valores; experimentação; carreira.
\end{abstract}

\begin{abstract}
The present article explores if the levels of ethical reflexivity can explain the existence of values of experimentation or adaptive responses of curiosity. A total of 488 male and female students (73.1\% girls), aged 18-53 $(M=21.9, S D=4.1)$, attending different years and university courses participated in the study. The results of hierarchical linear regression analyzes indicate that there are significant associations between the levels of ethical reflexivity in the career and curiosity and there is no relation between the levels of ethical reflexivity in the career and the subfunctioning experimentation.

Keywords; Ethical reflexivity; curiosity; values; experimentation; career.
\end{abstract}

Segundo Duarte (2009), as considerações éticas na construção da própria carreira já estão presentes nas reflexões dos jovens há algum tempo, no entanto, na sociedade atual, assumem maior significado psicológico, uma vez que, estamos perante uma mudança de paradigma, passando-se do estudo do comportamento das escolhas de carreira, para o estudo da importância que o trabalho tem na vida de cada indivíduo.

Esta é uma ideia base do paradigma construtivista presente, por exemplo, na Teoria da Construção da Vida de Savickas e cols. (2009) que refere que o indivíduo constrói representações da realidade na construção da carreira, pertencendo a carreira aos indivíduos e não às organizações.

Da mesma forma, Guichard (2005) refere que a construção da carreira se trata de um processo constante de construção e reconstrução dos "selfs" que cada indivíduo contém dentro de si. Dessa forma, surge o modelo de autoconstrução (Guichard, 2005, 2009), que combina três diferentes abordagens: uma perspetiva sociológica, uma perspetiva psicológica e uma perspetiva dinâmica. Segundo a perspetiva sociológica, o indivíduo encontra-se integrado numa sociedade e como tal, vai agir e interagir dentro desse contexto. $\mathrm{Na}$ perspetiva psicológica, o indivíduo vai adaptar elementos da categoria social para construir o seu self. Nesta perspetiva é salientado o caráter cognitivo da construção (Guichard, 2009). No que diz respeito à perspetiva dinâmica, Guichard (2009) considera duas formas de reflexividade na carreira: a antecipação reflexiva do self e a reflexividade "eu - tu - ele/ela". A antecipação reflexiva do self, constitui o processo primordial de nos relacionarmos connosco próprios, em que existe uma ligação do self e das suas experiências com uma entidade construída pelo mesmo, que possui caraterísticas desejáveis (Guichard, 2009). A segunda consiste na reflexividade "eu - tu - ele/ela". É por isso chamada de tríade ou reflexividade dialógica, existindo uma descentralização do self. Para Paul Ricoeur (2004), a verdadeira intenção ética constitui-se quando tanto o self, como o outro mais próximo mas também o outro mais distante são igualmente homenageados. Desta forma pensar na carreira implica pensar no bem pessoal, no bem social, assim como, num projeto de vida para os outros e com os outros (Ricoeur, 2004).

Mais recentemente, Marques (2015) propõe o Modelo Conceptual de Reflexividade Ética na Carreira. Neste modelo, a forma como os sujeitos pensam em relação à carreira divide-se em três níveis de reflexividade: o nível 1 , pensamento em espelho, em que o indivíduo se centra em si, nos seus interesses e competências; o nível 2, pensamento comparativo antecipatório, em que o jovem toma as suas decisões pensando em si mas também no 
outro mais próximo; e o nível 3, denominado de questionamento ético, em que o indivíduo inclui nas suas decisões o self, o outro mais próximo mas também o outro mais distante. Estes três níveis evoluem de forma hierárquica desde um nível de menor grau de complexidade até níveis mais elevados de reflexão (Marques, 2015).

Tal como a reflexividade ética, também os valores de vida têm sido vistos na literatura como um conceito importante na construção de carreira. Segundo Jesus (2013), os valores que o jovem apresenta podem favorecer ou desfavorecer o questionamento ético na construção da carreira.

A Teoria Funcionalista dos Valores Básicos de Vida (Gouveia, 2003; Gouveia et. al., 2008) tem vindo a ser desenvolvida nos últimos anos. Esta teoria parte da ideia de que os valores são formas de orientação que estão disponíveis a todos os indivíduos mas que são adotados de acordo com a experiência pessoal e do contexto sociocultural em que cada sujeito se encontra inserido (Gouveia, 1998). É uma teoria que se foca nas funções que os valores exercem. De acordo com a Teoria Funcionalista, os valores podem ser definidos como critérios de orientação que guiam as ações humanas e expressam as necessidades básicas. Desta forma, o seu principal foco está nas funções que os valores exercem, que são definidas como os aspetos psicológicos que estes cumprem ao guiar comportamentos e representar cognitivamente as necessidades humanas (Gouveia, 2013; Gouveia et. al., 2011).

A subfunção experimentação presente na Teoria Funcionalista de Gouveia (1998) diz respeito a necessidades fisiológicas de satisfação de prazer e associa-se a indivíduos que estão dispostos a inovações e mudanças nas estruturas de organização social. Esta subfunção torna-se importante nos dias de hoje, uma vez que com a globalização que ocorre no século XXI, a exploração de carreira deixa de estar relacionada apenas com profissão e com o emprego e passa a designar-se como um processo de aprendizagem e mudanças frequentes, tanto a nível do trabalho, como nos restantes domínios de vida (Savickas, 2005).

Marques (2015) refere que jovens com valores mais elevados na subfunção valorativa experimentação apresentam níveis mais elevados de reflexividade ética. Estes dados indicam que indivíduos que exploram o meio, que são curiosos, que procuram desfrutar da vida através da busca de novas aventuras ou de obter prazer apresentam níveis mais avançados de pensamento ético na carreira.

Segundo Taveira (2000), o conceito de curiosidade é um instinto básico e é habitualmente satisfeito através da exploração do Eu e do meio. Super (1980) refere que quando este comportamento exploratório é recompensado, interna ou externamente, permite a aquisição de conhecimento e despoleta nova exploração. No entanto, se não existir um reforço contingente à exploração, pode-se experienciar conflito e iniciar-se um novo processo de evitamento ou desistência face à exploração.

Tal como Marques (2015) refere, a curiosidade pode facilitar a tomada de decisões de carreira éticas e reflexivas. O jovem progride na sua capacidade de compreender e analisar quantidades cada vez maiores de informação, através de uma maior exploração do meio.

Sendo o ensino superior um contexto que facilita e promove o desenvolvimento do indivíduo, confrontando-o com novas ideias e experiências (Taveira, 2001) e uma vez que o início da vida adulta é marcado por processos de definição social e pessoal, considerando-se como uma fase de maior responsabilidade pessoal na tomada de decisões vocacionais (Arnett, 2006), acredita-se que também este meio será rico para que ocorra exploração e o desenvolvimento da reflexividade ética e dos valores básicos de vida.

Tendo por base este enquadramento teórico, e uma vez que existem evidências de que a reflexividade ética na carreira poderá predizer a subfunção valorativa experimentação, assim como a curiosidade (Marques, 2015), o objetivo deste estudo exploratório é estudar a reflexividade ética na carreira, os valores de experimentação e a curiosidade em jovens universitários, explorando se os níveis de reflexividade ética na carreira podem explicar a existência de valores de experimentação ou de respostas adaptativas de curiosidade nestes jovens.

Tendo em conta o enquadramento teórico e objetivo do estudo, prevê-se que maiores níveis de reflexividade ética na carreira sejam preditores de respostas adaptativas de curiosidade (H1) e da subfunção valorativa experimentação $(\mathrm{H} 2)$.

\section{Método}

\section{Participantes}

O estudo integra 488 estudantes universitários de 46 curso da Universidade do Minho, dos quais 367 são mulheres (73,1\%). A média de idades é de 21,9 anos (DP $=4,1$ ), sendo a idade mínima 18 anos e a máxima 53 anos. Destes estudantes, 456 são de nacionalidade portuguesa $(94,0 \%)$ e 29 de nacionalidade estrangeira $(6,0 \%)$. Apenas $61(12,5 \%)$ da totalidade afirmou ser trabalhador estudante.

\section{Instrumentos}

Questionário de dados demográficos. Trata-se de um questionário elaborado para o efeito da pesquisa, constituído por questões para recolha de informações pessoais do participante e do seu percurso académico.

Escala sobre Adaptabilidade na Carreira - Forma Universitária (Monteiro \& Almeida, 2015; Adaptado de Savickas \& Porfeli, 2012). Composta por vinte e oito itens, divididos em quatro subescalas: Preocupação, Confiança, Controlo e Curiosidade. Cada uma destas subescalas é composta por sete itens. Neste estudo só utilizamos a sub-escala Curiosidade, que se refere à busca de novas oportunidades, aprendizagens e atividades. A resposta aos itens é realizada através de uma escala de tipo Likert de 5 pontos, sendo que 1 corresponde a "Muito pouco" e 5 corresponde a "Muito". O coeficiente de alfa de Cronbach para a escala total é de .92 e para a subescala Curiosidade é de .84 (Monteiro \& 
Almeida, 2015), indicando propriedades psicométricas adequadas a esta população de estudantes universitários.

Questionário dos Valores Básicos (QVB, Gouveia et al., 2009). Composto por dezoito itens distribuídos por seis funções psicossociais: Experimentação (emoção, prazer e sexualidade), Realização (êxito, poder e prestígio), Interativa (afetividade, apoio social e convivência), Normativa (obediência, religiosidade e tradição), Existência (estabilidade pessoal, saúde e sobrevivência) e Suprapessoal (beleza, conhecimento e maturidade). A resposta aos itens é realizada através de uma escala de sete pontos, com os extremos "1 Totalmente não importante" e "7 - Extremamente Importante", em que foi pedido aos participantes que cotassem os valores, considerando o seu conteúdo. Verificam-se evidências de validade fatorial e consistência interna deste instrumento, em contexto brasileiro (Gouveia, 2003; Gouveia et al., 2009) e português (Marques, Silva, Taveira \& Gouveia, 2016).

Questionário Reflexividade Ética sobre a Carreira - Ensino Superior (Silva, Marques \& Taveira, 2016; adaptado de GERE, Marques, Silva \& Taveira, 2013). É um questionário escrito, composto por três situações de resposta aberta para recolher opiniões e modos de pensar dos participantes acerca de decisões de carreira. Estas situações avaliam a capacidade dos participantes considerarem as consequências das suas escolhas para si, em termos de satisfação e realização pessoais, para o 'ele/ela' mais próximos, nomeadamente o impacto nos mais significativos mas também para o 'outro' mais distante, quanto a questões como a sustentabilidade, justiça e bem-estar.

Para chegar aos níveis de pensamento ético realizou-se uma análise de conteúdo semiestruturada, recorrendo à Grelha de Categorias dos Conteúdos de Pensamento sobre a Carreira (GCCPC; Marques \& Silva, 2015), procedendo-se à validação desta grelha para estudantes universitários.

Grelha de Categorias dos Conteúdos de Pensamento sobre a Carreira (GCCPC; Marques \& Silva, 2015). Esta grelha é constituída por dois grandes grupos, sendo que um está relacionado com os fatores a ter em consideração no processo de tomada de decisão, incluindo quatro categorias gerais, nomeadamente Pessoa, Dificuldade, Planeamento e Exploração, e outro com a perceção das consequências possíveis das várias opções ponderadas, composto por três categorias gerais Relacionais, Bem-Estar e Económico-Políticas. Esta grelha foi validada, para avaliar discursos de jovens do $8^{\circ}$ ao $12^{\circ}$ ano de escolaridade obtendo-se valores de kappa de Cohen nunca inferiores a 60 (Landis \& Koch, 1977).

Validação da GCCPC com Estudantes Universitários. Foi realizada a validação da Grelha para o Ensino Superior, avaliando-se a concordância entre dois elementos avaliadores - acordo inter-juízes. Concretamente cada juiz atribuiu uma categoria a cada unidade de análise presente nos excertos escritos pelos participantes em resposta às situações apresentadas nos questionários. A codificação foi realizada de modo independente por cada juiz e registada numa base de dados, sendo esta composta por 4337 unidades de análise. No final da análise realizada por cada juiz, foram realizadas análises de diferenças inter-sujeitos de coeficiente kappa de Cohen (k). Para a validação da grelha utilizou-se $36,6 \%$ dos resultados (equivalente a 1734 unidades de análise), obtendo-se valores médios de kappa de Cohen de .91, DP = .1. Dado o valor médio de kappa de Cohen $(\mathrm{k}>.80)$, o nível de concordância é considerado Excelente (Landis \& Koch, 1977).

\section{Procedimento}

Recolha de dados. A recolha de dados ocorreu em salas de aula da Universidade do Minho e em salas de estudo da Biblioteca Geral desta Universidade.

O questionário foi preenchido de forma individual e presencial, num único momento temporal, sendo todos os participantes capazes de ler e compreender a língua portuguesa. Foram dadas as mesmas instruções a todos os participantes, garantindo a igualdade das condições de recolha. O tempo médio de realização dos questionários rondou os 30 minutos.

Todos os participantes preencheram o questionário de forma voluntária, após terem sido informados do objetivo do estudo, ter sido garantida a confidencialidade no tratamento e divulgação dos dados e tendo-se informado que poderiam abandonar a resposta ao inquérito, garantindo-se o cumprimento de todas as questões éticas inerentes.

Análise de dados. A análise qualitativa dos discursos dos jovens realizou-se recorrendo a uma metodologia de análise de conteúdo semi-estruturada, Para isso definiu-se de forma conjunta as unidades de contexto para cada situação (frase), seguida da definição das unidades de análise (ideia) presentes em cada unidade de contexto.

Após esta fase, procedeu-se à categorização do conteúdo das situações por dois elementos avaliadores, através da Grelha de Categorias dos Conteúdos de Pensamento sobre a Carreira (GCCPC; Marques \& Silva, 2015). No caso de desacordo entre os dois juízes, houve a intervenção de um terceiro juiz de modo a definir qual a categoria mais ajustada à unidade de análise que gerou desacordo. Após esta fase, através do Sistema de Avaliação da Reflexividade Ética na Carreira (Marques \& Silva, 2015), procedeu-se à equivalência das categorias aos níveis de pensamento ético na carreira apresentados no Modelo Conceptual da Reflexividade Ética na Carreira (Marques \& Silva, 2015).

As análises estatísticas realizaram-se através de regressões lineares hierárquicas no software de análise IBM SPSS. Estas análises permitiram analisar as relações entre os níveis de reflexividade ética na carreira e Curiosidade e a relação entre os níveis de reflexividade ética na carreira e a subfunção valorativa experimentação, na população estudada.

Para as análises realizadas, todos os pressupostos estavam cumpridos à excessão do pressuposto da ausência de outliers. No sentido de corrigir este pressuposto, procedeu-se à realização das análises estatísticas sem a presença dos outliers, no entanto, os resultados mantiveram-se. Dessa forma, foi decidido que não se iriam eliminar sujeitos, não havendo perda amostral. Assim, foi conduzida a análise, reconhecendo cuidados na generalização dos resultados (Field, 2009). 


\section{Resultados}

Na tabela 1 apresentam-se os resultados da análise de regressão linear hierárquica que foi conduzida para testar a hipótese $\mathrm{H} 1$.

Tabela 1

Reflexividade Ética na Carreira e Curiosidade: Modelo de regressão linear hierárquica.

\begin{tabular}{lcccc}
\hline & $\begin{array}{c}\mathrm{R} 2 \\
(\mathrm{R} 2 \mathrm{Aj} .)\end{array}$ & Modelo & $\beta$ & $t$ \\
\hline $1^{\circ}$ Bloco Nível 1 & .00 & $F(1,485)=$ & .05 & 1.20 \\
& $(.00)$ & 1.44 & & \\
$2^{\circ}$ Bloco Nível & .02 & $F(2,484)=$ & .02 & .05 \\
1+Nível 2 & $(.01)$ & $4.05^{*}$ & .12 & $2.58^{*}$ \\
& .02 & $F(3,483)=$ & .02 & .36 \\
$3^{\circ}$ Bloco Nível & $(.01)$ & $2.83^{*}$ & .12 & $2.46^{*}$ \\
1+Nível 2+Nível 3 & & & .03 & .63 \\
\hline$* p<.05$ & & & &
\end{tabular}

Como se pode observar na tabela, o $2^{\circ}$ bloco de regressão explica $2 \%$ da variância $(\mathrm{R} 2 \mathrm{Aj} .=.01)$, sendo estatisticamente significativo, $\mathrm{F}(2,484)=4.05, \mathrm{p}<.05$. No entanto, apenas o nível 2 de reflexividade ética constitui um preditor estatisticamente significativo da Curiosidade, $\beta=.12, \mathrm{t}=2.58, \mathrm{p}<.05$. O $3^{\circ}$ bloco de regressão explica $2 \%$ da variância $(\mathrm{R} 2 \mathrm{Aj} .=.01)$, sendo estatisticamente significativo, $\mathrm{F}(3,483)=2.83$, $\mathrm{p}<.05$. Também neste bloco, apenas o nível 2 de reflexividade ética constitui um preditor estatisticamente significativo da Curiosidade, $\beta=.12, \mathrm{t}=2.46, \mathrm{p}<.05$.

Na tabela 2 apresentam-se os resultados da análise de regressão linear hierárquica conduzida para testar a hipótese $\mathrm{H} 2$.

Tabela 2

Reflexividade Ética na Carreira e Experimentação: Modelo de regressão linear hierárquica.

\begin{tabular}{lcccc}
\hline & $\begin{array}{c}\mathrm{R} 2 \\
(\mathrm{R} 2 \mathrm{Aj} .)\end{array}$ & Modelo & $\beta$ & $t$ \\
\hline $1^{\circ}$ Bloco Nível & .03 & $F(1,484)$ & -.03 & .55 \\
1 & $(.00)$ & $=.30$ & & \\
$2^{\circ}$ Bloco Nível & .10 & $F(2,483)=$ & .00 & .05 \\
1+Nível 2 & $(.01)$ & 2.33 & -.10 & $-2.09^{*}$ \\
$3^{\circ}$ Bloco Nível & .01 & $F(3,482)=$ & -.00 & -.01 \\
1+Nível 2 & $(.01)$ & 1.61 & -.10 & $-2.12^{*}$ \\
+Nível 3 & & & .02 & .40 \\
\hline$* p<.05$ & & & &
\end{tabular}

Pode-se observar que tanto o primeiro, como o segundo, assim como o terceiro bloco, não são estatisticamente significativos. No entanto, no $2^{\circ}$ bloco, o nível 2 de reflexividade ética constitui um preditor estatisticamente significativo da Experimentação, $\beta=$ $.10, t=-2.09, p<.05$. Também no $3^{\circ}$ bloco de regressão, o nível 2 de reflexividade ética constitui um preditor estatisticamente significativo da Experimentação, $\beta=$ $.10, t=-2.12, p<.05$.

\section{Discussão}

Através das análises conduzidas, verificou-se a confirmação da hipótese $\mathrm{H} 1$, ou seja, níveis de reflexividade ética na carreira são preditores de respostas adaptativas de curiosidade. Nos blocos estudados, o nível 2 de reflexividade ética - Pensamento Comparativo Antecipatório, torna-se mais saliente, predizendo a curiosidade, ou seja, jovens adultos que se foquem mais no self, mas também no outro mais próximo estão mais propensos a respostas adaptativas de curiosidade. É também de frisar que, embora seja o nível 2 de reflexividade ética a contribuir mais para respostas de curiosidade, o terceiro bloco de regressão, em que o nível 2 coexiste com o nível 1 e o nível 3 de reflexividade ética, é também estatisticamente significativo. Dessa forma, apesar de não ser necessária a existência do nível 3 para a obtenção de respostas de curiosidade, conclui-se que a presença do nível 3 de reflexividade ética na carreira favorece respostas adaptativas de curiosidade.

Estes resultados vão ao encontro das evidências relatadas por Marques (2015) acerca da possível associação entre os níveis de reflexividade ética e a curiosidade. Também segundo Taveira (2001), o ensino superior é um contexto que facilita e promove o desenvolvimento do indivíduo, confrontando-o com novas ideias e experiências. Assim, é natural que respostas de curiosidade se destaquem nesta população. A saliência do nível 2 de reflexividade ética é corroborada por Guichard (2009), que refere que o indivíduo se encontra integrado numa sociedade e como tal, vai agir e interagir dentro desse contexto, sendo os outros próximos importantes para a construção do self. Assim, construímos a nossa realidade através dos outros, e para estarmos adaptados é necessários considerarmos os outros, principalmente aqueles que nos são mais próximos.

O facto do primeiro bloco não ser estatisticamente significativo não significa que a população estudada não pense no Nível 1 de Reflexividade Ética - Pensamento Espelho, uma vez que, como Marques (2015) refere, os três níveis de reflexividade ética evoluem de forma hierárquica desde um nível de menor grau de complexidade até níveis mais elevados de reflexão, e dessa forma para um indivíduo pensar em Nível 2 e Nível 3 , tem obrigatoriamente de pensar em Nível 1 de reflexividade ética.

No que diz respeito à Hipótese $\mathrm{H} 2$, os resultados obtidos mostram que tanto o primeiro, como o segundo, assim como o terceiro bloco não são estatisticamente significativos. Desta forma, conclui-se que, segundo os resultados obtidos, a reflexividade ética na carreira não prediz a experimentação, sendo esta hipótese refutada.

Segundo evidências de Marques (2015), a reflexividade ética na carreira poderia predizer a subfunção valorativa experimentação. Estas diferenças podem dever-se ao facto dos estudos de Marques (2015) terem sido desenvolvidos com população de faixas etárias mais jovens, numa fase de transição para a vida adulta, o que faz como que haja uma maior valorização de comportamentos de exploração e experimentação em relação às possíveis saídas para o ensino universitário ou para o mundo de trabalho. Outra razão para os resultados obtidos é o facto de a amostra ser constituída por estudantes que frequentam o ensino superior, e nestes estudantes a experimentação poderá não ser a subfunção 
mais saliente, ou relacionada com a forma como pensam as carreiras, podendo estes jovens valorizar mais outras subfunções valorativas como, por exemplo, a realização.

Relativamente ao método de recolha de dados, este foi diferente do utilizado por Marques (2015), o que pode ter influenciado as diferenças nos resultados, uma vez que os participantes responderam de forma mais direta às questões, mencionando por vezes categorias de nível 2 de reflexividade ética mas não de nível 1. No entanto, este método teve vantagens, uma vez que os discursos obtidos foram mais focados, o que ajudava a realçar o mais saliente, uma vez que a pessoa apenas referia o que é mais importante para si. Também o facto de não haver a presença de um entrevistador diminui a influência da desejabilidade social, obtendo-se um conteúdo mais puro.

De uma forma geral, o não cumprimento de todos os pressupostos e o baixo poder explicativo sugerem a necessidade de estudos futuros para aprofundar as relações entre a Reflexividade Ética na Carreira, Valores e Curiosidade.

Como desfecho, esperamos que este estudo possa suscitar o interesse para mais estudos neste âmbito de forma a desenvolver o conhecimento deste recente construto, Reflexividade Ética na Carreira, e de encontrar formas válidas para o avaliar e promover em intervenções de carreira.

\section{Referências}

Arnett, J. J. (2000). Emerging adulthood: A theory of development from the late teenagers through the twenties. American Psychologist, 55, 469-480.

Duarte, M. E. (2009). Um século depois de Frank Parsons: Escolher uma profissão ou apostar na Psicologia da construção da vida? Revista Brasileira de Orientação Profissional, 10(2), 5-14.

Field, A. (2009). Discovering statistics using SPSS (3 Edição). Londres: Sage Publications Ltd.

Gouveia, V. (1998). La naturaleza de los valores descriptores del individualismo y del colectivismo: Una comparación intra e intercultural. Tese de doutoramento não publicada. Departamento de Psicologia Social, Universidade Complutense de Madrid, Espanha.

Gouveia, V. (2003). A natureza motivacional dos valores humanos: Evidências acerca de uma nova tipologia. Estudos de Psicologia, 8, 431-443. doi: 10.1590/S1413-294X2003000300010

Gouveia, V., Meira, M., Gusmão, E., Filho, M., \& Souza, L. (2008). Valores humanos e interesses vocacionais: Um estudo correlacional. Psicologia em Estudo, 13, 603-611. doi: 10.1590/S1413-73722008000300022

Gouveia, V., Milfont, T., Soares, A., Andrade, P., \& Leite, I. (2011). Conhecendo os valores na infância: Evidências psicométricas de uma Medida. Psico-PUCRJ, 42(1), 106-115.

Gouveia, V. (2013). Teoria funcionalista dos valores humanos: Fundamentos, aplicações e perspectivas. São Paulo: Casa do Psicólogo.

Guichard, J. (2005). Life-long self-construction. International Journal for Educational and Vocational
Guidance, $\quad 5, \quad 111-124$. doi:10.1007/s10775-005-8789-y

Guichard, J. (2009). Self-constructing. Journal of Vocational Behavior, 75, 251-258. doi:10.1016/j.jvb.2009.03.004

Jesus, M. (2013). Condições do questionamento ético na carreira: Estudo dos valores básicos de vida de estudantes e professores do ensino básico e secundário. Tese de doutoramento. Escola de Psicologia, Universidade do Minho, Braga. Retirado de http://repositorium.sdum.uminho.pt/bitstream/1822/24 793/1/Maria\%20de\%20Jesus\%20Ferreira\%20Mira\%2 0Bezerra.pdf

Landis, R., \& Koch, G. (1977). The measurement of observer agreement for categorical data. Biometrics, 33, 159-174. doi: 10.2307/2529310

Marques, C. (2015). Valores Básicos de vida e Reflexividade ética na Carreira em Jovens. Tese de Doutoramento. Escola de Psicologia, Universidade do Minho, Braga. Retirado de https://repositorium.sdum.uminho.pt/bitstream/182 2/42555/1/Catia\%20Margarida\%20da\%20Cunha\%20 Marques.pdf

Marques, C., Silva, A. D., Taveira, M. C. \& Gouveia, V. (2016). Functional Theory of Values: Results of a Confirmatory Factor Analysis with Portuguese Youths. Revista Interamericana de Psicologia/Interamerican Journal of Psychology, 50(3), 392-401.

Monteiro, S. \& Almeida, L. S. (2015). The relation of career adaptability to work experience, extracurricular activities, and work transition in Portuguese graduate students. Journal of Vocational Behavior, 91, 106-112.

Ricoeur, P. (2004). Ethique: De la morale à l'éthique et aux éthiques. In M. Canto-Sperber. (Eds.), Dictionnaire d'étique et de philosophie morale (pp. 689-694). Paris: PUF.

Savickas, M. L. (2005). The theory and practice of career construction. In S. D. Brown \& R. W. Lent (Eds.), Career development and counseling: Putting theory and research to work (pp. 42-70). Hoboken, NJ: John Wiley \& Sons.

Savickas, M., Nota, L., Rossier, J., Dauwalder, J-P., Duarte, M. E., Guichard, J., Soresi, S., Van Esbroeck, R., \& Van Vianen, A. (2009). Life designing: A paradigm for career construction in the 21st Century. Journal of Vocational Behavior, 75, 239-250. doi:10.1016/jvb.2009.04.004

Savickas, M. L., \& Porfeli, E. J. (2012). Career Adapt-Abilities Scale: Construction, reliability, and measurement equivalence across 13 countries. Journal of Vocational Behavior, 80, 661-673.

Super, D. (1980). A life-span, life-space approach to career development. Journal of Vocational Behavior, 16, 282-298. doi:10.1016/0001-8791(80)90056-1

Taveira, M. C. (2000). Exploração e desenvolvimento vocacional de jovens: Estudo sobre relações entre a exploração, a identidade e a indecisão vocacional. Braga: Centro de Estudos em Educação e Psicologia, IEP, Universidade do Minho.

Taveira, M. C. (2001). O papel da universidade na orientação e desenvolvimento dos alunos: Contributos 
para um modelo de intervenção psicoeducacional. ADAXE - Revista de Estudios e Experiencias

Educativas, 17, 65-77. ISSN: 0213-4705 